\title{
ITER CS Model Coil and CS Insert Test Results
}

N. Martovetsky, P. Michael, J. Minervini, A. Radovinsky, M. Takayasu, R. Thome, T. Ando, T. Isono, T. Kato, H. Nakajima, G. Nishijima, $Y$. Nunoya, M. Sugimoto, $Y$. Takahashi, H. Tsuji, D. Bessette, K. Okuno, R. Ricci

This article was submitted to Applied Superconductivity Conference Virginia Beach, VA

September 17-22, 2000

U.S. Department of Energy

\section{September 07, 2000}

Lawrence

Livermore

National

Laboratory 


\section{DISCLAIMER}

This document was prepared as an account of work sponsored by an agency of the United States Government. Neither the United States Government nor the University of California nor any of their employees, makes any warranty, express or implied, or assumes any legal liability or responsibility for the accuracy, completeness, or usefulness of any information, apparatus, product, or process disclosed, or represents that its use would not infringe privately owned rights. Reference herein to any specific commercial product, process, or service by trade name, trademark, manufacturer, or otherwise, does not necessarily constitute or imply its endorsement, recommendation, or favoring by the United States Government or the University of California. The views and opinions of authors expressed herein do not necessarily state or reflect those of the United States Government or the University of California, and shall not be used for advertising or product endorsement purposes.

This is a preprint of a paper intended for publication in a journal or proceedings. Since changes may be made before publication, this preprint is made available with the understanding that it will not be cited or reproduced without the permission of the author.

This report has been reproduced

directly from the best available copy.

Available to DOE and DOE contractors from the Office of Scientific and Technical Information

P.O. Box 62, Oak Ridge, TN 37831

Prices available from (423) 576-8401 http://apollo.osti.gov/bridge/

Available to the public from the National Technical Information Service

U.S. Department of Commerce 5285 Port Royal Rd., Springfield, VA 22161

http://www.ntis.gov/

OR

Lawrence Livermore National Laboratory Technical Information Department's Digital Library http:/ / www.llnl.gov/tid/Library.html 


\title{
ITER CS Model Coil and CS Insert Test Results
}

\author{
N. Martovetsky, P. Michael, J. Minervini, A. Radovinsky, M. Takayasu, R. Thome, T. Ando, T. Isono, T.
} Kato, H. Nakajima, G. Nishijima, Y. Nunoya, M. Sugimoto, Y. Takahashi, H. Tsuji, D. Bessette, K. Okuno, M. Ricci

\begin{abstract}
The Inner and Outer modules of the Central Solenoid Model Coil (CSMC) were built by US and Japanese home teams in collaboration with European and Russian teams to demonstrate the feasibility of a superconducting Central Solenoid for ITER and other large tokamak reactors. The CSMC mass is about $120 \mathrm{t}$, OD is about $3.6 \mathrm{~m}$ and the stored energy is $640 \mathrm{MJ}$ at $46 \mathrm{kA}$ and peak field of $13 \mathrm{~T}$. Testing of the CSMC and the CS Insert took place at Japan Atomic Energy Research Institute (JAERI) from mid March until mid August 2000. This paper presents the main results of the tests performed.
\end{abstract}

Index Terms- Critical current, losses, superconducting magnets, instability.

\section{INTRODUCTION}

$\mathrm{T}$ HE CSMC and three insert coils were among the main deliverables from the ITER Engineering Design Activity, which started in 1992.

The 180 t test assembly consists of Inner Module [1], Outer Module [2] and the CS Insert [3] and the supporting structure. This is the largest cable-in-conduit conductor (CICC) magnet ever built with $640 \mathrm{MJ}$ stored energy at 46 $\mathrm{kA}$. It operates at a higher current than any other large superconducting magnet.

The CSMC used a heavy wall conduit, made from Incoloy 908 superalloy, which helped to utilize the superconducting properties of $\mathrm{Nb} 3 \mathrm{Sn}$ to the full extent.

The main objectives of the testing were validation of all ITER CSMC specifications, determination of the operational limits and verification of the design criteria for superconducting magnets for fusion.

The main goals of the test program were [4]:

1. Produce $13 \mathrm{~T}$ peak field in $\mathrm{DC}$ and a ramp mode of $0.4 \mathrm{~T} / \mathrm{s}$ consistent with ITER CS operation with a peak current of $46 \mathrm{kA}$.

2. Demonstrate operation of the CS Insert in the reverse mode at $-40 \mathrm{kA}$ in $13 \mathrm{~T}$

3. Demonstrate a margin of $2 \mathrm{~K}$ in a simulated ITER operational scenario.

4. Demonstrate that the CSMC can withstand high voltage discharge in a ITER relevant discharge mode, including 5-s detection time.

Manuscript received September 19,2000. This Work supported by the US Department of Energy under contract to the Lawrence Livermore National Laboratory (contract No. W-7405-Eng-48) also under MIT Grant No. DE-FC02-93ER54186-D\&T, and by Japanese government.

Author N.M. is with Lawrence Livermore National Laboratory, Livermore, CA 94550 USA (telephone: (925) 422 4269, e-mail: martovetskyl@llnl.gov).

P.M., J.M., A.R., M.T., R.T are with MIT Plasma Science and Fusion Center, Cambridge MA 02139, USA.

T.A., T.I., T.K., H.N., G. N., Y. N., M.S., Y.T., H.T. are with Japan Atomic Energy Research Institute, Naka-machi, Ibaraki-ken, Japan,

D. B., K.O. are with ITER Joint Central Team, Naka-machi, Ibarakiken, Japan

M.R. is with ENEA C.R. Frascati, Italy
5. Demonstrate stable operation of leads and joints.

6. Study losses, ramp rate limitation, stability against thermal disturbances, quench propagation and thermohydraulic characteristics and sensitivity to the cyclic operation.

The CSMC and the CS Insert were installed in the CSMC Test Facility at JAERI [5] in October 1999. From April 11 to August 18, 2000 the CSMC and the CS Insert were under test with current. About 350 experimental runs were performed in these tests. More than 400 sensors were used to acquire data and the amount of information stored during the test campaign is huge. This paper presents some of the first post-test analysis results.

\section{COOLDOWN AND THERMOHYDRAULICS}

The cool down started on March 13 and the coils became superconducting on April 4 with the first charging of the coil on April 11.

This cool down time in general was in line with the prediction of 600 hours, limited by the tie rod temperature.

A typical flow distribution through the conductors in the CSMC is reasonably uniform as shown in Fig. 1.

The supercritical pump provided a very steady flow with total capacity in excess of $500 \mathrm{~g} / \mathrm{s}$. Most of the experiments were conducted with a flow distribution close to the one shown in Fig. 1, however, elevated temperature measurements sometimes required lower flow - down to 2 $\mathrm{g} / \mathrm{s}$ in the conductors which were heated.

\section{DC PERFORMANCE OF THE CSMC AND THE CS INSERT}

\section{A. $C S M C$}

The DC tests were planned to reveal if the available

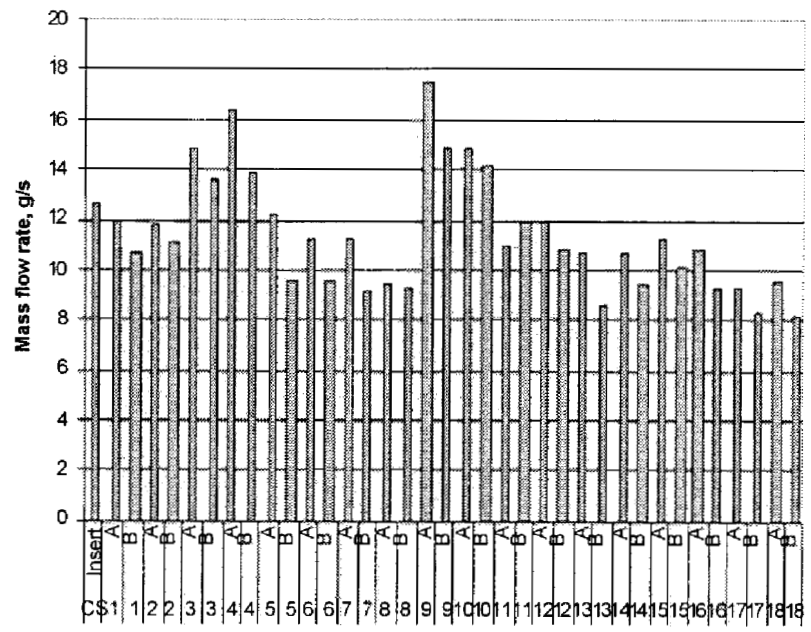

Fig. 1. Helium mass flow distribution in the CSMC and the CS Insert technology is capable of producing a magnet, which would fully utilize the superconductor property in a very high field and stress environment

The first charge to the full current of $46 \mathrm{kA}$ took place on 
April 19 without training. Several charges to $46 \mathrm{kA}$ at elevated temperature of $5.3 \mathrm{~K}$ were performed later to demonstrate that the magnet designed with $2 \mathrm{~K}$ margin is capable of reaching $100 \%$ of its rated current with no problem.

The current sharing temperature $\left(\mathrm{T}_{\mathrm{cs}}\right)$ and the critical current measurements were carried out on the conductor 1a, 11a and the CS Insert.

1) Conductors 1a and 11a $T_{c s}$.

Current sharing temperature $T_{c s}$ and critical current $I_{c}$ measurements at DC conditions showed that the superconducting properties of layer 1 , and of conductor la in particular, follow the ITER design guidance [6] based on L. Summers correlation [7]. Fig. 2 shows DC results measured on the layer 1. As seen from Fig.2, the current sharing measurement at constant current is consistent with the critical current measurement at a fixed temperature, which is evidence that the conductor properties reach its ultimate limit. The fitting parameters, describing the properties of the layer la are: $\mathrm{jc}=593 \mathrm{~A} / \mathrm{mm}^{2} @ 4.2 \mathrm{~K}, 12 \mathrm{~T}, \mathrm{e}=-0.25 \%, \mathrm{Tc} 0 \mathrm{~m}=18 \mathrm{~K}$, $\mathrm{Bc} 20 \mathrm{~m}=28 \mathrm{~T}$ ).

These fitting parameters show that the CSMC conductor exceeds the specified strand current density at $12 \mathrm{~T}$ and $4.2 \mathrm{~K}$ of $550 \mathrm{~A} / \mathrm{mm}^{2}$. The cable experienced a very low strain in the conductor resulting in high jc because of Incoloy 908 conduit and a proper design.

2) Layer $11 a$

Measurement results of layer 1la are summarized in Fig. 3. The critical current of layer 11a shows higher parameters than expected from the strand specifications or from the short sample data, which are higher than the specifications. Also, it was noted that the measured data do not fit well into a $\mathrm{L}$. Summers correlation [7] within a reasonable range of parameters. It is possible, that since the conductor 11a has a mixture of two different strands (Hitachi and Furukawa), the behavior of the Tcs in a mixed cable is different than for a single strand cable. These facts are yet to be analyzed in more detail. Nevertheless, it seems clear that conductor 11a does not show any sign of degradation.

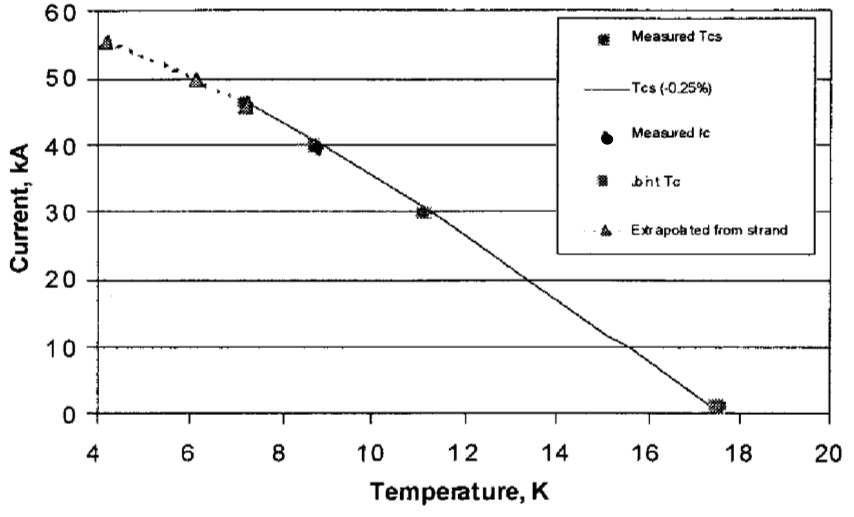

Fig. 2. Results of the DC tests on the layer 1 and a fitting curve [6].

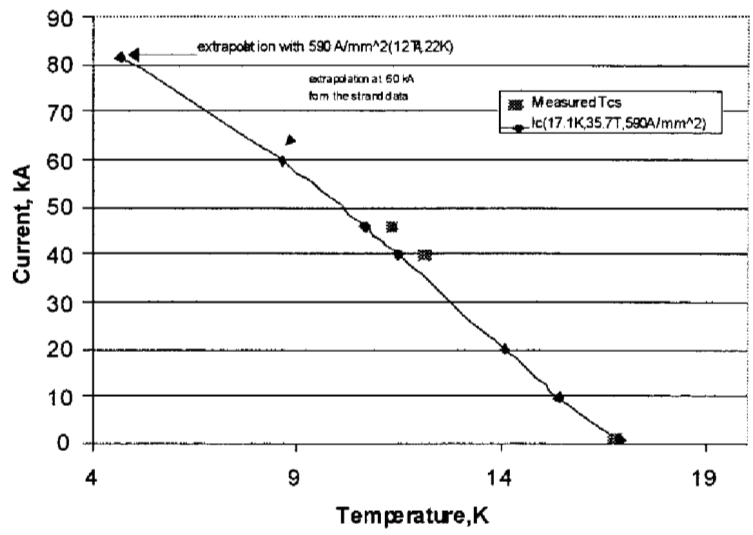

Fig. 3. Current sharing measurements on the conductor 11a

\section{3) CS Insert}

The $T_{c s}$ and $I_{c}$ were measured on the CS Insert in $13 T$ by varying background field from the CSMC. The $T_{c s}$ at $13 \mathrm{~T}$ and $40 \mathrm{kA}$, (nominal operation conditions of ITER-EDA) was $7.7 \mathrm{~K}$.

That satisfies the requirement of the temperature margin of $2 \mathrm{~K}$ for the maximum operating temperature of $5.3 \mathrm{~K}$. The measurement results slightly exceed the ITER design guidance as shown in Fig. 4. However, $j_{c}$ in a strand sample heat treated with the CS Insert was higher than $550 \mathrm{~A} / \mathrm{mm} 2$ of the ITER design guidance. Also, the strain in Nb3Sn strand is expected to be less than $-0.25 \%$ assumed in Fig. 4 due electro-magnetic force. Although these factors require more detailed analysis, it is clear that the CS Insert show small or no degradation as well.

\section{JOINTS}

The joints in any high current magnet like the CSMC and the CS Insert are very important elements, which could have become the limiting factor in the CSMC overall performance. Two types of the $46 \mathrm{kA}$ joints for the CSMC were developed and tested during an extensive R\&D program [8,9]: a lap joint and a butt joint. The requirements to have a low resistance, low DC and $\mathrm{AC}$ losses and high reliability in a high field and high $\mathrm{dB} / \mathrm{dt}$ environment made the joints quite complicated. Only a few cryogenic tests on prototypes were carried out to verify the joints performance in the R\&D effort and some improvements were made. The production effort of the CSMC exceeded the R\&D production by an order of magnitude and since during the R\&D stage we had a few joints, which failed to meet the 


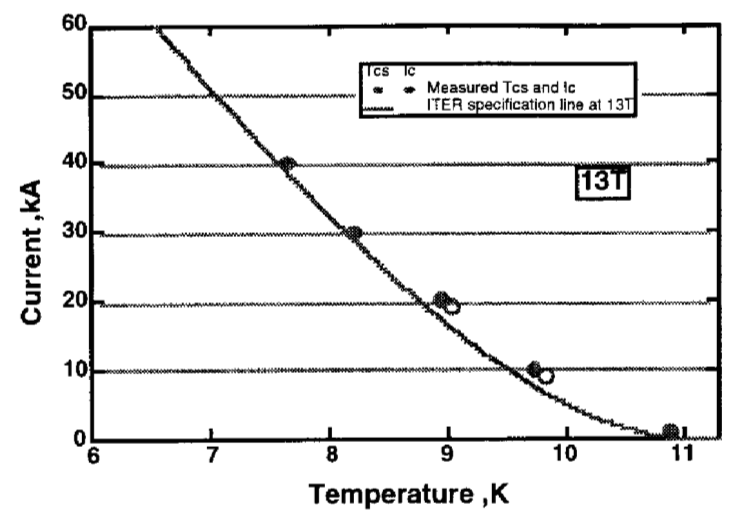

Fig. 4. Current sharing and critical current measurements on the CS Insert Coil.

specifications, there was a concern about possibility of a substandard joint in the test assembly. The CSMC testing was truly a verification test that provided very valuable data on the joint performance in the large magnet.

The R\&D effort on the joints showed, that electrical measurements made across the joints indicated a significantly lower heat generation than the real heat generation in the joint measured by calorimetry. This was caused by the current distribution near the joint in the relatively short test samples. In the CSMC it was expected that the current distribution would be more favorable due to the longer distance between joints.

Fig. 5 shows resistance of the joints measured by two independent ways - by electrical and by calorimetric methods.

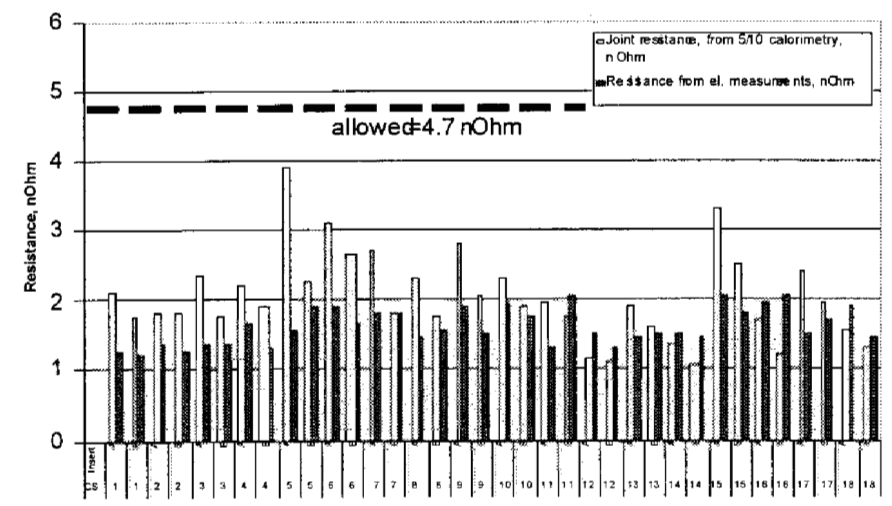

Fig. 5 Joint resistances in the CSMC and the CS Insert measured by electrical and calorimetry methods at $46 \mathrm{kA}$

It is seen that both joint designs (lap joints in layers 1-10 and butt joints in layers 11-18) provided resistances below the specifications in a quite reproducible manner. The two methods give very consistent and close results, much closer than in the short sample measurements during the $R \& D$ on the joints.

These results make the R\&D effort on the joints a big success and show that the high current, low resistance, low loss joints can be built in an industrial environment reliably. In no test runs at $4.5 \mathrm{~K}$, did the joints cause a quench or limit performance.

\section{AC LOSSES}

Loss measurements in the CSMC and the CS Insert were one of the most important elements of the Test Program. It was known from previous experiments that the short sample loss measurements do not always represent the losses in the magnet [10]. The scatter in the loss measurements on the short samples of relevant subscale and full-scale ITER conductors during the R\&D effort was very significant. The coupling loss time constant varied from several milliseconds to 30-50 ms per unit of strand volume [11-13]. It also varied greatly depending on mechanical load on the conductor and number of test cycles. In a 1-m OD CIC NbSn magnet test it was noticed that the losses decreased significantly as a result of the charge cycles [14], the same results were observed in the conductor samples [15]. Looking for this effect, the losses in CSMC and the CS Insert were measured periodically starting from the first shots till the very end of the test campaign. Many interesting phenomena were observed during the AC loss measurements, here we are presenting only a few major results.

\section{A. Hysteresis losses.}

The hysteresis losses in the conductors were measured in very slow ramps $(\mathrm{d} / / \mathrm{dt}=1 \mathrm{kA} / \mathrm{min})$ and were in line with expectations from the strand data. The IGC strand, used in the layers 5-8, and the Mitsubishi strand in the layers 10, 15 and 16 , which were made by the internal tin process, showed lower than expected hysteresis losses, which makes the internal tin strand a viable candidate for any layers, including the inner layers of the Central Solenoid for a future fusion machine.

\section{B. Coupling losses}

The coupling loss time constants for all conductors in the CSMC and the CS Inserts deduced from the $18 \mathrm{~s}$ discharge from $36.8 \mathrm{kA}$ on June 26 are shown in Fig.6.

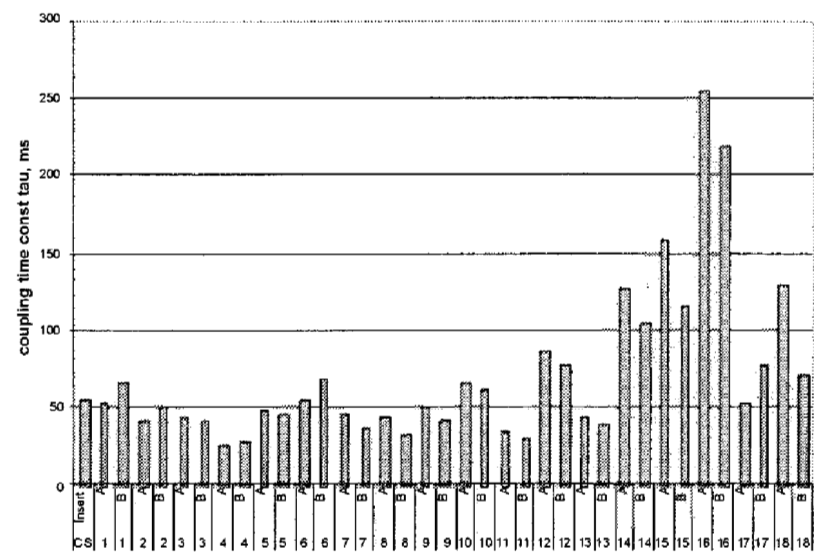

Fig. 6. Coupling time constant in the CSMC and CS Insert

The coupling losses in the CSMC showed several interesting features:

- Most of the conductors, except the CS Insert show significant and more or less monotonic reduction in losses (factor of 2 to 3 from the virgin state) with time and number of cycles.

- The coupling loss constant for Inner Module conductors is noticeably lower than for the Outer Module conductors, especially for the layers 14-16.

One of the possible explanations for the loss reduction is the electromagnetic load on the cable, which breaks the low 
resistance links between strands. Trying to find a quantitative correlation between number of cycles and the coupling losses, we introduced a term for the equivalent elapsed number of cycles $\mathrm{Np}$. The $\mathrm{Np}$ equals to the summation of $\left(\mathrm{B}_{\mathrm{j}} / \mathrm{B}_{1}\right)\left(\mathrm{I}_{\mathrm{p}} / 46\right)^{2}$ values, , where $\left(B_{i} / B_{1}\right)$ is the ratio between the average field in the layer " $i$ " and in the layer $1, I_{p}[k A]$ is the peak current in each test run. So, for example, a charge to $23 \mathrm{kA}$ would contribute in the first layer 0.25 to the $\mathrm{Np}$, while full charge to $46 \mathrm{kA}$ will contribute 1 , respectively smaller in the outer layers. Fig. 7 shows a correlation for the Inner Module selected layers, all of which seem to follow the same pattern. The Outer Module conductors demonstrate similar seemingly universal features.

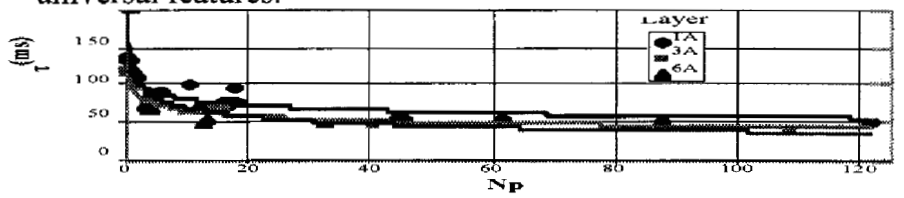

孟

Fig.7. Reduction of the coupling loss with number of equivalent cycles (see text for details)

\section{RAMP RATE LIMITATION}

The nominal ramp for the CSMC design was $0.4 \mathrm{~T} / \mathrm{s}$ for a charge to $13 \mathrm{~T}$. The pre-test analyses predicted that the maximum ramp rate, which the CSMC and the CS Insert would be able to withstand with no margin was $1.2 \mathrm{~T} / \mathrm{s}$.

The CS Insert withstood the $1.2 \mathrm{~T} / \mathrm{s}$ ramp to $13 \mathrm{~T}$, while CSMC conductor $1 \mathrm{~b}$ quenched in that run at about $11.8 \mathrm{~T}$ due to slightly higher and less uniform losses than in the CS Insert. This is very close to the pre-test analysis prediction.

The CSMC was successfully charged to $38 \mathrm{kA}$ at $1.9 \mathrm{~T} / \mathrm{s}$ and CS Insert had to be warmed to $6.5 \mathrm{~K}$ to quench it at 40 $\mathrm{kA}$ and $1.9 \mathrm{~T} / \mathrm{s}$ ramp. To establish if quench in the CSMC at high $\mathrm{dB} / \mathrm{dt}$ results from instability or from simple heating due to losses, we tried to calculate the maximum temperature in the conductor at the moment of the quench. We used noquench runs and the outlet/inlet data for the analysis. Fig. 8 shows the result of this analysis, which shows that the losses and corresponding heating are mostly responsible for the quench and electromagnetic instability and non-uniform current distribution in the conductor play a small role up to $0.6 \mathrm{~T} / \mathrm{s}$, although the deviation from the DC performance starts to grow at higher $\mathrm{dB} / \mathrm{dt}$ rates. These results and many other successful runs simulating the ITER operation scenarios, including plasma initiation, disruptions and much more severe conditions showed that the CSMC had relatively low ramp rate sensitivity up to $2 \mathrm{~T} / \mathrm{s}$.

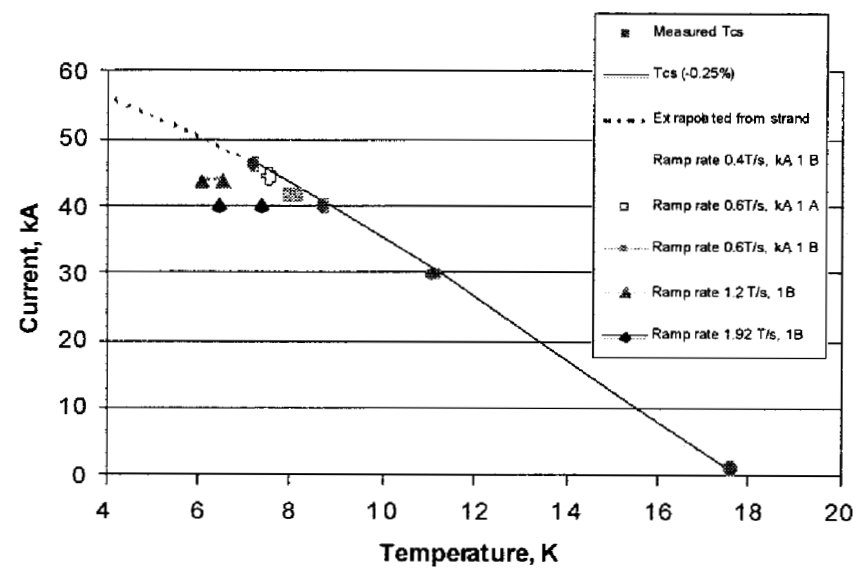

Fig.8 Peak temperature prior to quenches in the pulses versus DC current sharing temperature Tcs

\section{CONCLUSIONS}

All of the main goals of the Test Program were achieved. Performance of the CSMC and CS Insert demonstrated that:

1. Large scale, high field magnets can be designed, built and operated with little or no degradation of superconducting properties

2. High performance of the magnet fully justified the additional R\&D and fabrication effort spent on the Incoloy 908 jacket used in the CSMC and in the CS Insert.

3. The CSMC R\&D and fabrication effort developed the technology to build large fusion magnets with predictable properties for operation in demanding conditions

\section{ACKNOWLEDGMENT}

Well over a hundred people from many countries and organizations participated in this large and very successful project. The authors are grateful to all who contributed to this success.

\section{REFERENCES}

[1] R.J. Jayakumar, J.V. Minervini, J. Wohlwend, N. Martovetsky, R. Thome, "The USHT-ITER CS Model Coil Program Achievements", IEEE Trans. Appl. Superconductivity, vol. 10, No 1, pp.560-563, March 2000.

[2] T. Ando, T. Hiyama, Y. Takahashi, et .al, "Completion of the ITER CS Model Coil -Outer Module Fabrication", ibid, pp. 568-571.

[3] M. Sugimoto, T.Isono, Y.Nunoya et al, "Completion of CS Insert Fabrication", ibid, pp. 564-567

[4] "Test Description Document for ITER Central Solenoid Model Coil", ITER Document, Rev, 3.2, June 1998.

[5] S. Shimamoto, K. Hamada, T. Kato, et al, "Construction of ITER Common Test Facility for CS Model Coil, IEEE Trans. Mag., vol. 32, No. 4, p 3049, July 1996

[6] N. Mitchell et al, "Design Criteria:DDD1.1-1.3 Appendix C: Superconducting Magnet Design Criteria," ITER N11 DDD 32 97-1208 W 02, Dec 8, 1997.

[7] L.T. Summers, M.W. Guinan, J.R. Miller, P.A. Hahn, "A Model for the Prediction of Nb3Sn Critical Current as a Function of Field Temperature, Strain, and Radiation Damage," IEEE Trans. $M A G-27$, No. 2, p.2041, (1991)

[8] N. Martovetsky, J. Jayakumar, R. Manahan, P. Michael et al, "Development and Test of the ITER Conductor Joints for the central solenoid", Presented at the Annual American Nuclear Society meeting, Nashville, June 1998

[9] Y. Takahashi, Y. Nunoya, G. Nishijima et al, "Development of 46-kA Nb3Sn Conductor Joint for ITER Model Coils", IEEE Trans. Appl. Superconductivity, vol. 10, No 1, pp.580-583, March 2000. 
[10] Takataro Hamajima, Satoshi Hanai, Yoshihiro Wachi, Nicolai Martovetsky et al "Test results of the $100 \mathrm{kWh}$ SMES model coil - AC loss performance," Cryogenics 39 (11) (1999) pp. 947-953.

[11] D. Ciazynski, B. Turck, J.L. Duchateau, C. Meuris, "Current Distribution in 40kA NbTi and Nb3Sn Conductors for NET/ITER", IEEE Trans. Mag., vol. 27, No. 2, pp 2194, March 1991

[12] P. Bruzzone, A.M. Fuchs, G. Vecsey, E.Zapretilina, 'Test results for the high field conductor of the ITER Central Solenoid Model Coil" Presented at CEC conference, Montreal, July 13-16, 1999

[13] Y. Takahashi, "Results of the CS conductor JAERI tests", private communication

[14] [4] E.P. Balsamo, D.Ciazynski, O.Cicchelli et al, "Direct measurement of the AC loss of an ITER relevant coil", Physica C 310 (1998) p.258-261

[15] A. Nijhuis, N.H.W. Noordman, H.H.J. ten Kate et al., "Electromagnetic and Mechanical Characterization of ITER CS-MC Conductors affected by Transverse Cyclic Loading, Part 1: Interstrand Coupling Losses", IEEE Trans. Appl. Superconductivity, vol. 9, No 2, pp.1069-1072, June 1999. 
University of California

Lawrence Livermore National Laboratory

Technical Information Department

Livermore, CA 94551

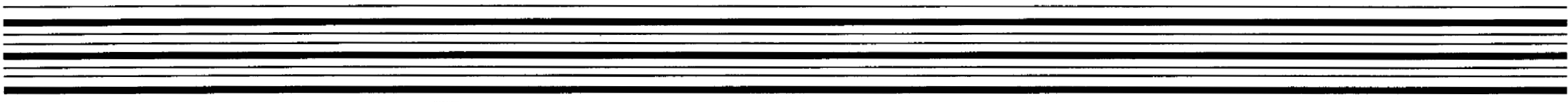

